\title{
KONDISI TUTUPAN KARANG PULAU KAPOPOSANG, KABUPATEN PANGKAJENE KEPULAUAN, PROVINSI SULAWESI SELATAN
}

\author{
Adelfia Papu ${ }^{1)}$ \\ ${ }^{1)}$ Program Studi Biologi FMIPA Universitas Sam Ratulangi Manado 95115
}

\begin{abstract}
ABSTRAK
Telah dilakukan penelitian untuk menentukan kondisi tutupan karang di Pulau Kapoposang, Kabupaten Pangkajene, Provinsi Sulawesi Selatan. Pulau Kapoposang merupakan salah satu Daerah Perlindungan Laut (DPL) di Indonesia dan data kondisi tutupan karang merupakan informasi yang sangat penting untuk mengontrol kondisi laut tersebut. Sampling dengan menggunakan metode transek garis menunjukkan bahwa rata-rata persentase tutupan karang sebesar 48,53\% dan tergolong tutupan sedang.
\end{abstract}

Kata kunci: Tutupan karang, Pulau Kapoposang

\section{CORAL COVERING CONDITION IN KAPOPOSANG ISLAND, DISTRICT OF PANGKAJENE KEPULAUAN, SOUTH SULAWESI}

\begin{abstract}
A research was carried out to determine the condition of Coral covering in Kapoposang Island, District of Pangkajene Kepulauan, South Sulawesi. Kapoposang Island is one of Marine Protected Area (MPA) in Indonesia and data of coral covering condition is very important information to control the marine area. Transect line method for sampling showed that average percentage of coral covering was $48,53 \%$ and it was classified as moderate coral reef covering.
\end{abstract}

Keywords: Coral covering, Kapoposang Island

\section{PENDAHULUAN}

\section{Latar Belakang}

Pulau Kapoposang merupakan salah satu Daerah Perlindungan Laut (DPL) yang terdapat di dalam gugusan Kepulauan Spermonde. Pulau Kapoposang Terletak di Kecamatan Liukang Tupabiring Selatan. 'Kapoposang' diambil bahasa Bugis berarti; kepulauan ini dianggap menempati posisi relatif paling ujung yang 'penghabisan' atau yang 'terakhir'. Pulau ini juga dikelilingi oleh substrat yang sebagian besar berupa terumbu karang, dan sebagian kecil lamun.

Tipe ekosistem yang ada di perairan Pulau Kapoposang adalah ekosistem terumbu karang dengan keanekaragaman jenis flora dan fauna yang cukup tinggi dengan tingkat keterwakilan sekitar 55\% dan 70\%. Menurut BKSDA (1997) ekosistem terumbu karang merupakan salah satu ekosistem yang rapuh sehingga tergolong ke dalam ekosistem yang laju kepunahannya relatif cepat bila mendapat gangguan. Laju kepunahan flora adalah $45 \%$ sedangkan untuk fauna 65\%; komposisi organisme penyusun rantai makanan pada ekosistem perairan tersebut mulai dari produsen primer, konsumen tingkat pertama seterusnya sampai mangsa, pemangsa, pengurai dan top karnivora masih cukup lengkap. Berbagai jenis binatang mencari makan dan berlindung di ekosistem ini (Soekarno, 2003; Timotius, 2003; Barnes, 2005).Kondisi ekosistem terumbu karang tersebut menjadikan Pulau Kapoposang sebagai Taman Wisata Alam Laut (TWAL).

Taman Wisata Alam laut (TWAL) Kapoposang merupakan salah satu tipe perwakilan terumbu karang tepi/datar, lamun dan mangrove di Sulawesi. Terumbu karang tepi merupakan ekosistem utama yang mengelilingi perairan Kapoposang. Terumbu tersebut membentuk daratan (reef flat) sampai sejauh 200 meter sampai tubir, dengan kedalaman 1-10 meter pada saat air surut (Faizal, 2010).

Terumbu karang merupakan koloni karang yang menjadi struktur di dasar laut berupa deposit kalsium karbonat $\left(\mathrm{CaCO}_{3}\right)$ di laut yang dihasilkan terutama oleh hewan 
karang yang merupakan hewan tak bertulang belakang, termasuk dalam Filum Coelenterata (hewan berongga) atau Cnidaria. Yang disebut sebagai karang (coral) mencakup karang dari Ordo scleractinia dan Sub kelas Octocorallia (kelas Anthozoa) maupun kelas Hydrozoa.

Satu individu karang atau disebut polip karang memiliki ukuran yang bervariasi mulai dari yang sangat kecil $1 \mathrm{~mm}$ hingga yang sangat besar yaitu lebih dari 50 $\mathrm{cm}$. Namun yang pada umumnya polip karang berukuran kecil. Polip dengan ukuran besar dijumpai pada karang yang soliter.

Salah satu sifat dari karang disebut akresi. Akresi adalah bentuk pertumbuhan koloni dan terumbu ke arah vertikal maupun horisontal. Karang dalam pertumbuhannya membentuk koloni, yang kemudian koloni tersebut berbentuk khas dan unik.

Variasi bentuk pertumbuhan koloni tersebut meliputi:

a. Bercabang/ branching

Koloni ini tumbuh ke arah vertikal maupun horisontal, dengan arah vertikal lebih dominan. Percabangan dapat memanjang atau melebar, sementara bentuk cabang dapat halus atau tebal. Karang bercabang memiliki tingkat pertumbuhan yang paling cepat, yaitu bisa mencapai $20 \mathrm{~cm} /$ tahun. Bentuk koloni seperti ini, banyak terdapat di sepanjang tepi terumbu dan bagian atas lereng, terutama yang terlindungi atau setengah terbuka.

b. Padat/masiv

Pertumbuhan koloni lebih dominan ke arah horisontal daripada vertikal. Karang ini memiliki permukaan yang halus dan padat; bentuk yang bervariasi, seperti setengah bola, bongkahan batu, dan lainnya; dengan ukuran yang juga beragam. Dengan pertumbuhan $<1$ $\mathrm{cm} /$ tahun, koloni tergolong paling lambat tumbuh. Meski demikian, di alam banyak dijumpai karang ini dengan ukuran yang sangat besar. Umumnya ditemukan di sepanjang tepi terumbu karang dan bagian atas lereng terumbu.

\section{c. Lembaran/foliose/flat}

Pertumbuhan koloni terutama ke arah horisontal, dengan bentuk lembaran yang pipih. Umumnya terdapat di lereng terumbu dan daerah terlindung.

d. Seperti meja/tabulate

bentuk bercabang dengan arah mendatar dan rata seperti meja. Karang ini ditopang dengan batang yang berpusat atau bertumpu pada satu sisi membentuk sudut atau datar.

Pertumbuhan karang dipengaruhi oleh faktor alam dan manusia. Faktor alam seperti ketersediaan nutrisi, predator, kondisi kimia-fisika laut, jika dalam keadaan sesuai maka dapat membuat kondisi terumbu karang lebih stabil. Faktor manusia, seperti pengeboman ikan, penggunaan jangkar di daerah terumbu karang yang merusak terumbu karang.

Diketahui bahwa ekosistem terumbu karang dihuni oleh lebih dari 93.000 spesies, bahkan diperkirakan lebih dari satu juta spesies mendiami ekosistem ini. Ekosistem terumbu karang yang sangat kaya akan plasma nutfah ini, kendati tampak sangat kokoh dan kuat, namun ternyata sangat rentan terhadap perubahan lingkungan. Penyusun utama ekosistem ini adalah hewan karang dari golongan Coelenterate, yang merupakan struktur di dasar laut berupa deposit kalsium karbonat di laut. Karang hidup berasosiasi dengan organisme lain dalam suatu ekosistem. Pertumbuhan karang dipengaruhi oleh faktor abiotik dan biotik.

- Faktor abiotik dapat berupa intensitas cahaya, lama penyinaran, suhu, nutrisi, dan sedimentasi. Karang memiliki kemampuan hidup dalam perairan miskin nutrien dan mampu beradaptasi terhadap kenaikan nutrien yang bersifat periodik, seperti runoff. Karang tidak dapat beradaptasi terhadap kenaikan nutrien secara mendadak dalam jumlah besar.

- Faktor biotik meliputi predasi, kompetisi, agresi karang lain, dan lainnya.

\section{Tujuan Penelitian}

Penelitian ini bertujuan untuk mendata bentuk kehidupan terumbu karang dan kondisi tutupan karang untuk selanjutnya dijadikan pertimbangan dalam pengelolaan dan recovery terumbu karang di Pulau Kapoposang.

\section{METODE PENELITIAN}

\section{Waktu dan Lokasi}

Penelitian dilakukan pada bulan Maret-Juni 2010 di sekitar Pulau Kapoposang, Pangkep. Analisis data dilakukan di Laboratorium Fisika dan 
Laboratorium Ilmu Kelautan Universitas Hasanuddin, Makassar.

\section{Alat dan Bahan}

Alat selam (SCUBA DIVING), salinometer, thermometer, tali transek.

\section{Pengambilan Data}

Penelitian dilakukan di sekitar Pulau Kapoposang, Kabupaten Pangkep. Lokasi penelitian dibagi menjadi empat stasiun, yaitu:

(I) Utara, merupakan daerah sloope, tidak ada pulau terdekat di arah utara, substrat dominan oleh batuan besar, di daerah patahannya terdapat terumbu karang yang berkembang dengan bagus.

(II) Timur, merupakan daerah yang berbatasan dengan beberapa pulau seperti pulau Gondong Bali, Pamanggangan dan Saranti. Dekat dengan daerah lamun, namun substrat di stasiun ini banyak berupa pecahan karang dan karang yang ditumbuhi alga.

(III) Selatan merupakan daerah flat, berbatasan dengan pulau terdekat (Pulau Pandangan). Substratnya dominan karang.

(IV) Barat, berbatasan langsung dengan Selat Makassar, namun masih merupakan daerah flat.

Terumbu karang didata dengan pengambilan data penutupan karang, dengan menggunakan transek garis sepanjang $50 \mathrm{~m}$. Data dicatat dan diukur dengan ketelitian hingga satuan $\mathrm{cm}$. Adapun kategori yang diamati adalah $\mathrm{LC}=$ Life Coral, $\mathrm{DC}=$ Dead Coral, $\mathrm{A}=$ Algae, $\mathrm{OT}=$ Others dan $\mathrm{ABT}=$ Abiotic.

Analisis data menggunakan rumus sebagai berikut (English et. al. 1994):

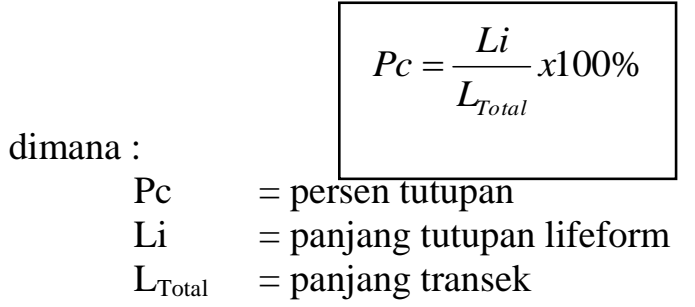

Penentuan kondisi terumbu karang dilakukan berdasarkan penutupan karang hidup (UPMSC, 1979 dalam Brown, 1986) berdasarkan kriteria pada Tabel 1 .
Tabel 1. Kriteria penentuan kondisi terumbu karang berdasarkan persentase penutupan karang hidup.

\begin{tabular}{|l|c|}
\hline KONDISI & $\begin{array}{c}\text { PERSENTASI PENUTUPAN } \\
\text { KARANG HIDUP }(\%)\end{array}$ \\
\hline Sangat Baik & $75-100$ \\
Baik & $50-74,9$ \\
Sedang & $25-49,9$ \\
Rusak & $0-24,9$ \\
\hline
\end{tabular}

Kondisi terumbu karang akan dikelompokkan menurut stasiun dan zona terumbu karang dan disajikan dalam bentuk tabel dan dianalisis secara deskriprif.

\section{HASIL DAN PEMBAHASAN}

\section{a. Kondisi Substrat}

Kondisi substrat berdasarkan hasil pengamatan disajikan pada Tabel 2, berupa gambaran tutupan karang yang mendominasi substrat di sekitar Pulau Kapoposang.

Pengamatan pada Stasiun I (sebelah Utara) dilakukan di kedalaman 7-15 meter. Pengamatan transek dilakukan di daerah drop off (Lampiran 1). Secara umum substrat yang dominan adalah abiotik (ABT) 54,9\% diwakili oleh batuan (Rock). Terdapat juga $24,24 \%$ karang hidup (LC) golongan Scleractina atau hard coral non Acropora. Selain itu tutupan substrat juga berupa Other Fauna (OT) 20,86\% (soft coral 2,8\%, sponge $8,38 \%$ dan others $9,68 \%$ ).

Pengamatan substrat pada Stasiun II (sisi Timur) dengan kedalaman 5-10 meter. Daerah ini didominasi oleh Other Fauna jenis karang lunak (Soft Coral) dengan prosentase penutupan $40,43 \%$. Selain jenis karang hidup juga terdapat jenis penutupan oleh Dead Coral (Dead Coral Algae/DCA) dengan prosentase penutupan $39,96 \%$. Jumlah penutupan oleh Life Coral sebesar $14,61 \%$ yang diwakili oleh jenis karang branching dan massive, Komposisi substrat selanjutnya adalah abiotik diwakili oleh Rubble 5\%. Di sekitar Stasiun II terdapat daerah laguna dan merupakan jalur kapal yang singgah di Pulau Kapoposang. Data dapat dilihat pada Lampiran 2. 
Tabel 2. Gambaran substrat Tiap Stasiun

\begin{tabular}{|c|c|c|c|c|c|c|c|c|}
\hline \multirow{2}{*}{ Stasiun } & $\begin{array}{c}\text { Zona Terumbu } \\
\text { Karang }\end{array}$ & \multirow{2}{*}{ kedalaman } & \multicolumn{5}{|c|}{ Benthic lifeform (\%) } & Kondisi \\
\cline { 3 - 8 } & & LC & OT & A & ABT & DC & karang \\
\hline I & Reef Slope & $7-15$ meter & $\mathbf{2 4 , 2 4}$ & $\mathbf{2 0 , 8 6}$ & $\mathbf{0}$ & 54,90 & 0 & sedang \\
\hline II & Reef Flat & $5-10$ meter & $\mathbf{1 4 , 6 1}$ & $\mathbf{4 0 , 4 3}$ & $\mathbf{0}$ & 5,00 & 39,96 & baik \\
\hline III & Reef Flat & $3-7$ meter & $\mathbf{4 4 , 3 2}$ & $\mathbf{4 , 9 0}$ & $\mathbf{5 , 6 6}$ & 38,56 & 6,56 & baik \\
\hline IV & Reef Flat & $1-5$ meter & $\mathbf{2 4 , 2 4}$ & $\mathbf{1 4 , 8 6}$ & $\mathbf{0}$ & 60,90 & 0 & sedang \\
\hline \hline
\end{tabular}

Stasiun III (sebelah selatan) dengan kedalaman 3-7 meter berada di antara Pulau Kapoposang dan Pulau Papandangan. Substrat yang paling dominan adalah dari jenis karang hidup (Life Coral) dengan prosentase penutupan sebesar $44,32 \%$ selain itu terdapat juga tutupan dari komponen abiotik yang mendominasi dengan prosentase penutupan sebesar $38,56 \%$ (rubble $21,4 \%$, rock $13,26 \%$ dan sand $3,9 \%$ ). Jenis lain yaitu DCA dengan prosentase penutupan 6,56\%, Alga sebesar 5,66\% (Halimeda 5,42\% dan Coralline Algae 0,24\%). Selain itu terdapat juga other fauna dengan prosentase penutupan sebesar 4,9\% (soft coral 4,28\%, sponge $0,42 \%$ dan others $0,2 \%$ ) yang datanya terlampir pada Lampiran 3.

Pada Stasiun IV (Barat) yang berhadapan dengan Selat Makassar, transek diletakkan di kedalaman 1-5 m (Lampiran 4). Pada kedalaman tersebut kategori life form Abiotik paling mendominasi dengan prosentase penutupan 60,9\%, (Rock 54,9\% dan Sand 6\%). Karang hidup (LC) menutupi sekitar 24,24\% dari substrat. Komponen Other Fauna sebesar 14,86\% (soft coral $0,8 \%$, sponge $10,38 \%$ dan others $9,68 \%$ ) juga menutupi permukaan substrat di Stasiun ini.

\section{KESIMPULAN}

Tutupan karang di Pulau Kapoposang secara umum berada pada kondisi sedang $(48,53 \%)$.

\section{SARAN}

Perlunya recovery terumbu karang di daerah ini karena kondisinya belum seperti yang diharapkan (kondisi baik atau lebih dari 50\% tutupan karang)

\section{DAFTAR PUSTAKA}

Barnes, R. D., Edward Ruppert, 1994. Invertebrate Zoology Sixth Edition, Saunder College Pubh, USA.

[BKSDA] Badan Konservasi Sumber Daya Alam, 1997. Laporan Pelaksanaan Badan Konservasi Sumber Daya Alam (BKSDA) Rencana Pengelolaan Taman Wisata Alam Kepulauan Kapoposang Kabupaten Pangkajene dan Kepulauan Propinsi Sulawesi Selatan. Direktorat Kerjasama Jendral Pembangunan Daerah dengan Direktorat Jenderal Perlindungan Hutan dan Pelestarian Alam. Hal 1-30.

Faizal, A., Jamaluddin J. 2010. Model Elevasi Digital untuk Mendeteksi Kerusakan Terumbu Karang di Taman Wisata Alam Laut Kapoposang, Sulawesi Selatan. Jurnal Ilmu kelautan Vol 1 Edisi Khusus: 1-12.

Soekarno, R. 2003. Pengelolaan Perikanan Terumbu Karang, Artikel trend/ popular Coremap.

Timotius, S. 2003. Biologi Terumbu Karang. Makalah Training Course. http://www.satudunia.oneworld.net/file s/biologikarang.pdf. Diakses 14 Maret 2008. 
Lampiran 1. Hasil Pengamatan Kondisi Terumbu Karang Stasiun I.

\begin{tabular}{|l|l|}
\hline Reef Name & P. Kapoposang/utara \\
\hline $\begin{array}{l}\text { Site Description/ } \\
\text { Transect length }\end{array}$ & Drop OFF/5000 cm \\
\hline & $22-A p r-09 / 16.30-$ \\
Date / Time & 18.16 Wita \\
\hline
\end{tabular}

\begin{tabular}{|c|c|c|c|}
\hline Benthic Lifeform & $\begin{array}{l}\text { Code } \\
\text { NBR }\end{array}$ & $\begin{array}{c}\text { Percent } \\
\text { Cover }\end{array}$ & $\begin{array}{c}\text { Category } \\
\text { Totals }\end{array}$ \\
\hline $\begin{array}{l}\text { Hard Corals } \\
\text { (Acropora) }\end{array}$ & & & \\
\hline Branching & $\mathrm{ACB}$ & 0 & \\
\hline Tabulate & ACT & 0 & \\
\hline Encrusting & ACE & 0 & \\
\hline Submassive & $\mathrm{ACS}$ & 0 & \\
\hline $\begin{array}{l}\text { Digitate } \\
\text { Hard Corals } \\
\text { (Non-Acropora) }\end{array}$ & $\mathrm{ACD}$ & 0 & 0 \\
\hline Branching & $\mathrm{CB}$ & 0.38 & \\
\hline Massive & $\mathrm{CM}$ & 1.86 & \\
\hline Encrusting & $\mathrm{CE}$ & 20.6 & \\
\hline Submassive & CS & 0 & \\
\hline Foliose & $\mathrm{CF}$ & 1.4 & \\
\hline Mushroom & CMR & 0 & \\
\hline Millepora & CME & 0 & \\
\hline Heliopora & $\mathrm{CHL}$ & 0 & \\
\hline Life Coral & & & 24.24 \\
\hline $\begin{array}{l}\text { Dead } \\
\text { Scleractinia }\end{array}$ & & & \\
\hline $\begin{array}{l}\text { Dead Coral } \\
\text { With Algal } \\
\text { Covering }\end{array}$ & $\begin{array}{c}\mathrm{DC} \\
\mathrm{DCA}\end{array}$ & $\begin{array}{l}0 \\
0\end{array}$ & \\
\hline Dead Coral & & & 0 \\
\hline Macro & MA & 0 & \\
\hline Turf & TA & 0 & \\
\hline Coralline & $\mathrm{CA}$ & 0 & \\
\hline Halimeda & HA & 0 & \\
\hline Algal Assemblage & AA & 0 & \\
\hline Algae & & & 0 \\
\hline Other Fauna & & & \\
\hline Soft Corals & $\mathrm{SC}$ & 2.8 & \\
\hline Sponge & SP & 8.38 & \\
\hline Zoanthids & $\mathrm{ZO}$ & 0 & \\
\hline Other & OT & 9.68 & \\
\hline Others & & & 20.86 \\
\hline Abiotic & & & \\
\hline Sand & $\mathrm{S}$ & 0 & \\
\hline Rubble & $\mathrm{R}$ & 0 & \\
\hline Silt & SI & 0 & \\
\hline Water & WA & 0 & \\
\hline
\end{tabular}

\begin{tabular}{|l|r|r|r|} 
Rock & RCK & 54.9 & \\
\hline Abiotic & & & 54.9 \\
\hline Total & & & 100 \\
\hline
\end{tabular}

Lampiran 2. Hasil Pengamatan Kondisi Terumbu Karang Stasiun II.

\begin{tabular}{|l|l|}
\hline Reef Name & kapoposang/timur \\
\hline $\begin{array}{l}\text { Site Description / } \\
\text { Transect length }\end{array}$ & Tubir / $5000 \mathrm{~cm}$ \\
\hline Date / Time & 22-Apr-09 / 08.00-09.10 \\
\hline
\end{tabular}

\begin{tabular}{|c|c|c|c|}
\hline $\begin{array}{c}\text { Benthic } \\
\text { Lifeform }\end{array}$ & $\begin{array}{l}\text { Code } \\
\text { NBR }\end{array}$ & $\begin{array}{c}\text { Percent } \\
\text { Cover }\end{array}$ & $\begin{array}{c}\text { Category } \\
\text { Totals }\end{array}$ \\
\hline $\begin{array}{l}\text { Hard Corals } \\
\text { (Acropora) }\end{array}$ & & & \\
\hline Branching & ACB & 4.85 & \\
\hline Tabulate & ACT & 0 & \\
\hline Encrusting & ACE & 0 & \\
\hline Submassive & ACS & 0 & \\
\hline $\begin{array}{l}\text { Digitate } \\
\text { Hard Corals } \\
\text { (Non- } \\
\text { Acropora) }\end{array}$ & $\mathrm{ACD}$ & 0 & 4.85 \\
\hline Branching & $\mathrm{CB}$ & 5.26 & \\
\hline Massive & $\mathrm{CM}$ & 4.5 & \\
\hline Encrusting & $\mathrm{CE}$ & 0 & \\
\hline Foliose & $\mathrm{CF}$ & 0 & \\
\hline Mushroom & CMR & 0 & \\
\hline Millepora & CME & 0 & \\
\hline Heliopora & CHL & 0 & 9.76 \\
\hline Life Coral & & & 24.24 \\
\hline $\begin{array}{l}\text { Dead } \\
\text { Scleractinia } \\
\text { Dead Coral } \\
\text { With Algal } \\
\text { Covering }\end{array}$ & $\begin{array}{c}\mathrm{DC} \\
\mathrm{DCA}\end{array}$ & $\begin{array}{r}0 \\
39.96\end{array}$ & \\
\hline Dead Coral & & & 39.96 \\
\hline $\begin{array}{l}\text { Algae } \\
\text { Macro } \\
\text { Turf } \\
\text { Coralline } \\
\text { Halimeda } \\
\text { Algal } \\
\text { Assemblage }\end{array}$ & $\begin{array}{l}\text { MA } \\
\text { TA } \\
\text { CA } \\
\text { HA } \\
\text { AA }\end{array}$ & $\begin{array}{l}0 \\
0 \\
0 \\
0\end{array}$ & \\
\hline Algae & & & 0 \\
\hline $\begin{array}{l}\text { Other Fauna } \\
\text { Soft Corals } \\
\text { Sponge } \\
\text { Zoanthids } \\
\text { Others }\end{array}$ & $\begin{array}{l}\text { SC } \\
\text { SP } \\
\text { ZO } \\
\text { OT }\end{array}$ & $\begin{array}{r}40.43 \\
0 \\
0 \\
0\end{array}$ & \\
\hline Others & & & 40.43 \\
\hline
\end{tabular}




\begin{tabular}{|l|c|r|r|} 
Abiotic & & & \\
Sand & S & 0 & \\
Rubble & R & 5 & \\
Silt & SI & 0 & \\
Water & WA & 0 & \\
Rock & RCK & 0 & \\
Abiotic & & & 5 \\
\hline Total & & & 100 \\
\hline
\end{tabular}

Lampiran 3. Hasil Pengamatan Kondisi Terumbu Karang Stasiun III.

\begin{tabular}{|l|l|}
\hline Reef Name & kapoposang/selatan \\
\hline $\begin{array}{l}\text { Site Description / } \\
\text { Transect length }\end{array}$ & flat / $5000 \mathrm{~cm}$ \\
\hline & $22-A p r-09 / 10.15-$ \\
Date / Time & 11.37 \\
\hline
\end{tabular}

\begin{tabular}{|c|c|c|c|}
\hline Benthic Lifeform & $\begin{array}{l}\text { Code } \\
\text { NBR }\end{array}$ & $\begin{array}{c}\text { Percent } \\
\text { Cover }\end{array}$ & $\begin{array}{c}\text { Category } \\
\text { Totals } \\
\end{array}$ \\
\hline $\begin{array}{l}\text { Hard Corals } \\
\text { (Acropora) }\end{array}$ & & & \\
\hline Branching & ACB & 24.32 & \\
\hline Tabulate & ACT & 0 & \\
\hline Encrusting & $\mathrm{ACE}$ & 0 & \\
\hline Submassive & ACS & 0 & \\
\hline Digitate & $\mathrm{ACD}$ & 0 & 24.32 \\
\hline $\begin{array}{l}\text { Hard Corals } \\
\text { (Non-Acropora) }\end{array}$ & & & \\
\hline Branching & $\mathrm{CB}$ & 10.76 & \\
\hline Massive & $\mathrm{CM}$ & 3.84 & \\
\hline Encrusting & $\mathrm{CE}$ & 2.6 & \\
\hline Submassive & $\mathrm{CS}$ & 0 & \\
\hline Foliose & $\mathrm{CF}$ & 0 & \\
\hline Mushroom & CMR & 0 & \\
\hline Millepora & CME & 2.8 & \\
\hline Heliopora & CHL & 0 & 20 \\
\hline Life Coral & & & 44.32 \\
\hline $\begin{array}{l}\text { Dead } \\
\text { Scleractinia }\end{array}$ & & & \\
\hline Dead Coral & $\mathrm{DC}$ & 0.2 & \\
\hline With Algal & & & \\
\hline Covering & DCA & 6.36 & \\
\hline Dead Coral & & & 6.56 \\
\hline Algae & & & \\
\hline Macro & MA & 0 & \\
\hline Turf & TA & 0 & \\
\hline Coralline & $\mathrm{CA}$ & 0.24 & \\
\hline Halimeda & HA & 5.42 & \\
\hline Algal Assemblage & AA & 0 & \\
\hline Algae & & & 5.66 \\
\hline Other Fauna & & & \\
\hline Soft Corals & $\mathrm{SC}$ & 4.28 & \\
\hline Sponge & SP & 0.42 & \\
\hline Zoanthids & $\mathrm{ZO}$ & 0 & \\
\hline
\end{tabular}

\begin{tabular}{|l|c|r|r|} 
Others & OT & 0.2 & \\
Others & & & 4.9 \\
Abiotic & & & \\
Sand & S & 3.9 & \\
Rubble & R & 21.4 & \\
Silt & SI & 0 & \\
Water & WA & 0 & \\
Rock & RCK & 13.26 & \\
Abiotic & & & 38.56 \\
\hline Total & & & 100 \\
\hline
\end{tabular}

Lampiran 4. Hasil Pengamatan Kondisi Terumbu Karang Stasiun IV.

\begin{tabular}{|l|l|}
\hline Reef Name & kapoposang/barat \\
\hline $\begin{array}{l}\text { Site Description / } \\
\text { Transect length }\end{array}$ & Tubir / 5000 cm \\
\hline Date / Time & 22-Apr-09/10.15-11.37 \\
\hline
\end{tabular}

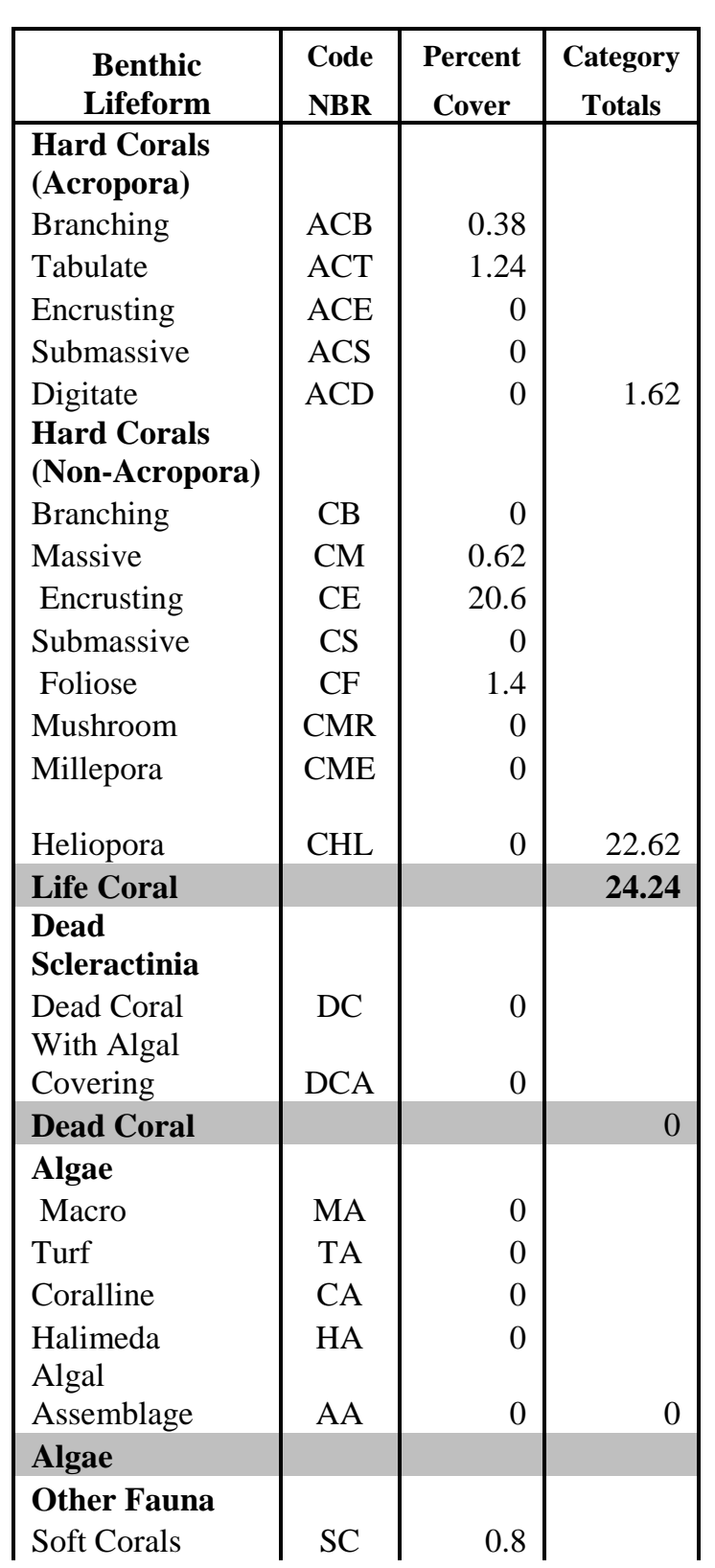




\begin{tabular}{|c|c|c|c|c|c|c|c|}
\hline $\begin{array}{l}\text { Sponge } \\
\text { Zoanthids } \\
\text { Others }\end{array}$ & $\begin{array}{l}\text { SP } \\
\text { ZO } \\
\text { OT }\end{array}$ & $\begin{array}{r}10.38 \\
0 \\
3.68\end{array}$ & & $\begin{array}{l}\text { Silt } \\
\text { Water } \\
\text { Rock }\end{array}$ & $\begin{array}{c}\text { SI } \\
\text { WA } \\
\text { RCK }\end{array}$ & $\begin{array}{r}0 \\
0 \\
54.9\end{array}$ & \\
\hline Others & & & 14.86 & Abiotic & & & 60.9 \\
\hline Abiotic & & & & Total & & & 100 \\
\hline Sand & S & 6 & & & & & \\
\hline Rubble & $\mathrm{R}$ & 0 & & & & & \\
\hline
\end{tabular}

Lampiran 5. Tabel kondisi lingkungan di Pulau Kapoposang.

\begin{tabular}{|l|c|c|c|c|c|}
\hline & stasiun & suhu $\left({ }^{0} \mathrm{C}\right)$ & salinitas $(\mathrm{ppm})$ & waktu (jam) & Sisi \\
\hline sampling 1 & I & 30 & 34 & 16.45 & utara \\
\hline $22 / 04 / 09$ & II & 32 & 35 & 9.41 & Timur \\
\hline & III & 32 & 34 & 12.36 & Selatan \\
\hline & IV & 32 & 34 & 11.58 & Barat \\
\hline sampling 2 & I & 29.3 & 32.2 & $18: 05$ & utara \\
\hline $9 / 5 / 09$ & II & 29.7 & 33 & $17: 31$ & Timur \\
\hline & III & 30.2 & 32.7 & $16: 49$ & Selatan \\
\hline & IV & 29.1 & 33.1 & $18: 30$ & Barat \\
\hline
\end{tabular}

